\title{
PENGARUH LATIHAN KEKUATAN OTOT TUNGKAI DENGAN BEBAN BERBASIS PANTAI TERHADAP PENINGKATAN KEMAMPUAN LARI 50 METER SISWA EKSTRAKURIKULER SMP NEGERI 8 KAUR
}

\author{
Aditya Julianto \\ Program Studi Pendidikan Jasmani, email : adityajulianto82@gmail.com Universitas Bengkulu \\ Tono Sugihartono \\ Universitas Bengkulu \\ Ari Sutisyana \\ Universitas Bengkulu
}

\begin{abstract}
Abstrak
Penelitian ini bertujuan untuk mengetahui Pengaruh Latihan Kekuatan Otot Tungkai Dengan Beban Berbasis Pantai Terhadap Peningkatan Kemampuan Lari 50 Meter Siswa Ekstrakurikuler SMP Negeri 8 Kaur. Penelitian ini adalah penelitian penelitian kuantitatif dengan menggunakan metode quasi eksperimen (semu). Penelitian ini menggunakan desain penelitian one group pretest-postes Design. Populasi adalah siswa putra SMP Negeri 8 Kaur dan sampelnya berjumlah 30 siswa dengan teknik total sampling. Instrumen yang digunakan dalam penelitian ini adalah tes digunakan pada pretes dan posttes. Setelah proses perlakuan diperoleh data ratarata pretes 10,52 dan rata-rata posttes adalah 9,42. Berdasarkan uji statistic diperoleh thitung sebesar 3,28 dan $t_{\text {tabel }}$ dengan taraf signifikansi $5 \%$ sebesar 1,69913. Karena $t_{\text {hitung }}>t_{\text {tabel }}$ maka dapat disimpulkan bahwa hipotesis kerja dapat diterima. artinya bahwa latihan otot tungkai berbasis beban pantai berpengaruh terhadap peningkatan prestasi lari 50 meter.
\end{abstract}

Kata kunci : Otot Tungkai, Beban Berbasis Pantai, Kemampuan Lari 50 Meter

\begin{abstract}
This study aims to determine the Effect of Leg Muscle Strength Exercises with Beach-Based Load on 50-Meter Running Capability in Extracurricular Students of SMP Negeri 8 Kaur. This research is a quantitative research using quasi-experimental methods. This study uses the research design of one group pretest-posttest design. The population is male students of SMP Negeri 8 Kaur and the sample is 30 students with totalsampling techniques. The instrument used in this study was a test used in the pre test and posttest. After the treatment process, the average pretest data is 10.52 and the average posttest is 9.42. Based on the statistical test obtained tcount of 3,28 and table with a 5\% significance level of 1.69913. Because tcount $>$ ttable, it can be concluded that the working hypothesis is acceptable because it is significant. This means that beach load-based leg muscle training has an effect on increasing the 50 meter run performance.
\end{abstract}

Keywords: Leg Muscle, Beach Based Load, 50 Meter Running Ability 


\section{PENDAHULUAN}

Pendidikan Jasmani adalah bidang kajian yang relatif masih muda, dan di Indonesia peran dari pendidikan Jasmani masih belum diperhatikan dengan sunguhsunguh. Hal ini dapat diamati dari kuarang seriusnya pemerintah terhadap mata pelajaran ini. Mata pelajaran pendidkan jasmani sering diabaikan dan dianggap sebagai mata pelajaran pelengkap saja, padahal di Negara-negara maju mata pelajaran pendidikan jasmani adalah salah satu mata pelajaran yang menjadi tumpuan dalam rangka meningkatkan dan memacu untuk hidup lebih aktif (Pujianto, 2013:1).

Dalam peraturan pemerinta Republik Indonesia No.19 tahun 2005 tentang standar nasional pendidikan ayat 1 butir $\mathrm{E}$ mata pelajaran penjaskes dimaksud untuk meningkatkan potensi fisik serta menanam sportifitas dan kesadaran hidup sehat. Karna itu olahraga mempunyai arti dan fungsi tersendiri didalam membina individu dan masyarakat (Candra, 2015: 1).

Berdasarkan jabaran dari tujuan pendidikan nasional tersebut, maka pembinaan dan pengembangan tersebut merupakan sarana untuk meningkatkan kualitas manusia dari aspek jasmani, kepribadian, disiplin, dan sportifitas. Untuk itulah pendidikan jasmani perlu dikembangkan di dunia keolahragaan Indonesia. Olahraga merupakan aktivitas fisik yang dapat membantu mengoptimalkan perkembangan tubuh melalui gerakan-gerakan yang didasari dengan gerak otot. Karakteristik olahraga secara langsung berkaitan dengan ciri-ciri prilaku manusia dan dengan berbagai macam kegiatan di masyarakat. Premis yang telah berkembang menyebutkan bahwa inti dari kegiatan olahraga adalah bermain dan bergerak, dengan keadaan itupula manusia memperagakan ketrampilannya dalam melakukan suatu gerakan.

Salah satu tujuan berolahraga yaitu untuk meningkatkan kesegaran jasmani. Kesadaran masyarakat untuk melakukuan olahraga semakin tinggi, istilah pendidikan jasmani dipergunakan untuk membedakan dengan istilah olahraga dalam pengertiannya yang luas. Pengertian pendidikan jasmani menurut iro pendidikan jasmani kementrian pendidikan pengajaran dan kebudayaan (1961) adalah pendidikan yang mengaktualisasikan potensi-potensi aktivitas manusia berupa sikap, tindakan dan karya diberi untuk, isi, dan arah untuk menuju kedaulatan kepribadian sesuai dengan cita-cita kemanusiaan (Candra, 2015: 1).

Berdasarkan pengertian tersebut dapat di rumuskan sebagai berikut: pendidikan olahraga dan kesehatan adalah suatu peroses pendidikan yang diarahkan untuk mendorong, membimbing, mengembangkan, dan membina kemampuan jasmani dan rohani serta kesehatan siswa dan lingkungan hidupnya, agar tumbuh dan berkembang jasmani dan rohani serta kesehatan siswa dan lingkungan hidupnya agar tumbuh dan berkembang secara harmonis dan optimal sehingga mampu melaksanakan tugas bagi dirinya dan pengembangan bangsa, (Subagiyo,2004:1.14). Atletik adalah gabungan dari beberapa jenis olahraga yang secara garis besar dapat dikelompokan menjadi lari, lempar, dan lompat. Kata ini berasal dari kata yunani "athlon" yang berarti "kontes". atletik merupakan cabang olahraga yang di perlombakan pada olimpiade pertama pada 776 SM. Induk olaharga organisasi untuk olahraga atletik di indonesia adalah PASI (Persatuan Atletik Seluruh Indonesia) (Kurniawan, 2017:13). 
Cabang yang disebut induk atau ibu dari olahraga adalah atletik. Nomor yang diperlombakan dalam atletik ada beberapa macam, diantaranya adalah lari, lempar, lompat, dan tolak. Nomor lari jarak pendek adalah 50, 200, 400 m, sedangkan jarak menengah yang di lombakan adalah $800 \mathrm{~m}$, dan $1500 \mathrm{~m}$. Untuk jarak jauh adalah 300, $5000,5000 \mathrm{~m}$, dan marathon $(42,195 \mathrm{~km})$. Sedangkan untuk lempar adalah lempar cakram, lempar martil, untuk tolak adalah tolak pluru, dan lompat adalah lompat jauh, lompat tinggi, lompat galah, lompat jangkit (Feri Kurniawan, 2017:13).

Sejak diadakan olimpiade kuno tahun

776 SM. Atletik sudah di perlombakan termasuk lari. Sejak itu atletik selalu menjadi cabang yang di perlombakan dalam setiap penyelengaraan pesta olahraga dunia yaitu olimpiade (moderen) sampai dengan saat ini. Untuk itulah pengenalan, pembinaan dan pengembangan olahraga atletik ini sangat penting di kenal sebagai dasar pendidikan olahraga bagi siswa, agar siswa mendapat kemudahan dalam menngikuti kegiatan-kegiatan olahraga khususnya pada nomor lari.

Lari adalah langkah yang dipercepat sehingga pada waktu berlari ada kecendrungan badan melayang. Ini berarti pada waktu lari kedua kaki tidak menyentuh tanah atau sekurang-kurangnya satu kaki tetap menyentuh tanah.

Lari merupakan bagian nomor cabang olahraga atletik yang pada dasarnya dapat di jadikan tiga bagian besar, yaitu nomor lari jarak pendek (sprint), nomor lari jarak menengah (middle distanc running), dan nomor lari jarak jauh (long distanc running). Di samping ketiga bagian nomor lari tersebut, masih ada nomor-nomor lari lainnya, yaitu lari sambung atau estafet (relay), lari gawang (hurdle), dan lari halang rintang (steeple chase).
Kondisi fisik dan penguasaan teknik yang baik akan dapat memberikan sumbangan yang cukup besar bagi siswa untuk mencapai prestasi olahraga khususnya nomor lari jarak pendek, banyak sekali bentuk latihan yang perlu di berikan di antaranya adalah kekuatan otot tungkai. Berdasarkan pengamatan dan tinjauan teoritis tentang bentuk latihan lari jarak pendek, terdapat unsur-unsur berupa kekuatan, kecepatan, daya ledak, ketepatan, keseibangan, reaksi dan kordinasi gerakan. Ada beberapa aspek yang harus di kuasai oleh pelari jarak pendek, seperti yang di sebutkan Catur Surya Widodo, (2014:36): "Lari jarak pendek bila dilihat dari tahap-tahap berlari terdiri dari beberapa tahap, yaitu: 1) Tahap reaksi dan dorongan. 2) Tahap percepatan. 3) Tahap transisi atau perubahan. 4) Tahap kecepatan maksimum. 5) Finish.

Berdasarkan hasil wawancara dan tes lari siswa yang peneliti lakukan bersama guru penjas di SMP Negeri 8 Kaur didapat informasi bahwa masih rendahnya kemampuan lari sprint yang dilakukan oleh siswa, hanya 7 dari 30 siswa yang berhasil melakukan lari sprint dengan baik, kurangnya kemampuan siswa dalam melakukan lari sprint disebabkan karena masih kurangnya latihan-latihan yang terarah untuk meningkatkan kondisi fisik yang menyangkut kecepatan lari sprint 50 meter.

Berdasarkan masalah yang dikembangkan di atas maka peneliti berkeinginan meneliti pengaruh latihan otot tungkai terhadap kemampuan lari 50 meter dengan judul penelitian "Pengaruh Latihan kekuatan Otot Tungkai Dengan Beban Berbasis Pantai Terhadap Peningkatan Kemampuan Lari 50 Meter Siswa Ekstrakurikuler SMP Negeri 8 Kaur" 
Pada penelitian yang telah dilakukan oleh peneliti ini, peneliti melakukan penelitian dengan dua tahap yaitu pretest dan postes dimana pretes dilakukan sebelum adanya .

\section{Kemampuan Lari $\mathbf{5 0}$ Meter Siswa}

a. PreTest

Untuk jumlah sampel pada penelitian ini adalah 30 siswa. Berdasarkan pretest yang dilakukan dengan menggunakan instrument penelitian pada 30 orang sampel diperoleh nilai maksimum 11,78 dan nilai minimium 9,07 rata-ratanya adalah 10,52

Berikut tabel distribusi frekuensi kelompok A pretest:

Tabel 4.1 Hasil Tes awal Lari 50 Meter Siswa

\begin{tabular}{l|l|l} 
No. & $\begin{array}{l}\text { Deskripsi } \\
\text { Statistik }\end{array}$ & Jumlah \\
\hline 1 & Nilai Maksimum & 11,78 \\
\hline 2 & Nilai Minimum & 9,07 \\
\hline 3 & Rata-rata (Mean) & 10,52
\end{tabular}

Untuk lebih jelasnya lagi dapat dilihat pada grafik berikut:

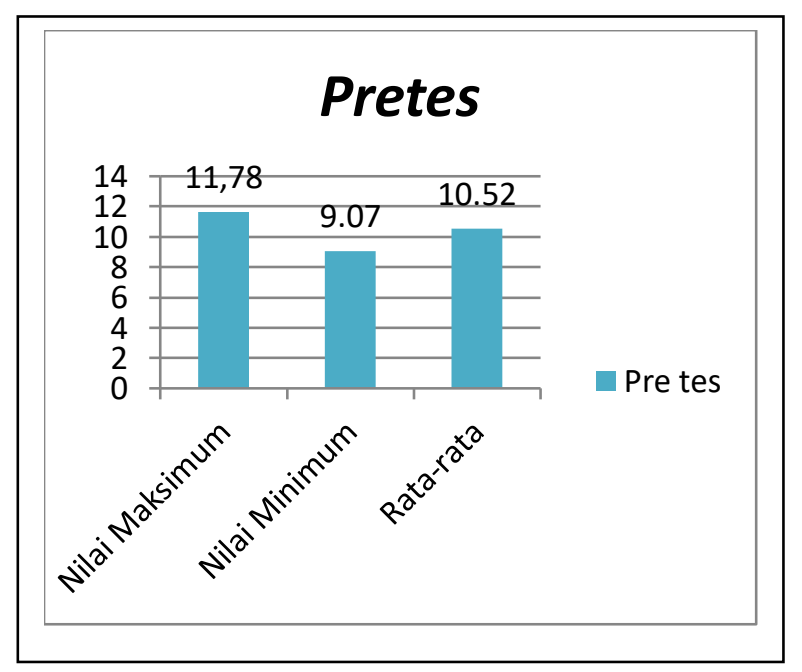

Gambar 4.1. Histogram Distribusi Skor Lari 50 Meter

\section{b. Posttest}

Berikut tabel distribusi frekuensi Postest:

Tabel 4.2 Hasil Tes Akhir Lari 50 Meter

\begin{tabular}{l|l|l} 
No. & $\begin{array}{l}\text { Deskripsi } \\
\text { Statistik }\end{array}$ & Jumlah \\
\hline 1 & Nilai Maksimum & 10,16 \\
\hline 2 & Nilai Minimum & 8,05 \\
\hline 3 & Rata-rata (Mean) & 9,42
\end{tabular}

Untuk lebih jelasnya lagi dapat dilihat pada grafik berikut:

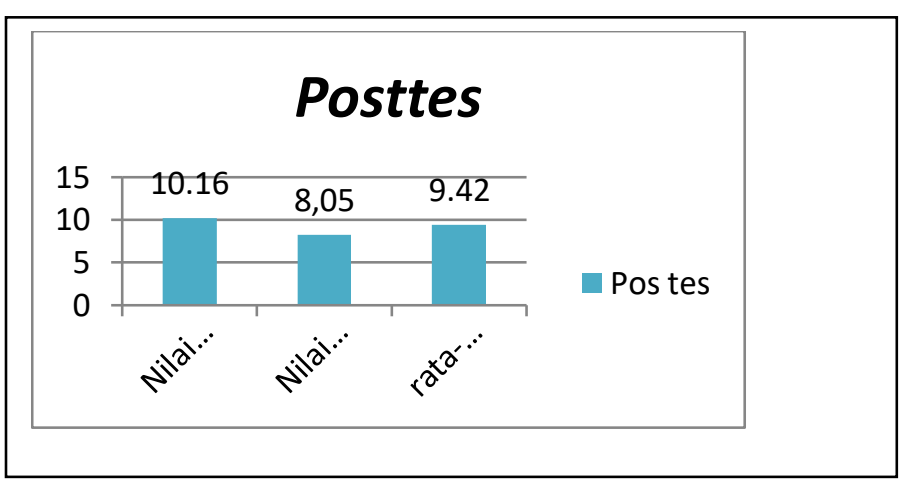

Gambar 4.2. Histogram Distribusi Skor Lari
50 Meter Akhir

\section{A. Deskripsi Hasil Uji Pra Syarat}

Sebelum melakukan pengujian terhadap hipotesis yang diajukan dalam penelitian ini, maka terlebih dahulu dilakukan uji prasyarat analisis data, yaitu uji normalitas data dan uji homogenitas.

1. Uji Normalitas Data

Hasil uji normalitas data masingmasing variabel disajikan dalam tabel berikut ini : 


\section{Tabel 4.3 Hasil Uji Normalitas Data}

\begin{tabular}{c|l|c|c|c} 
No & Variabel & $X_{\text {hitung }}$ & $X_{\text {tabel }}$ & $\begin{array}{c}\text { Keteranga } \\
n\end{array}$ \\
\hline 1 & Pretest & 24,860 & 42,557 & Normal \\
\hline 3 & Postest & 9,964 & 42,557 & Normal
\end{tabular}

Tabel diatas menunjukkan bahwa hasil pengujian untuk pretest skor $X_{\text {hitung }}=24,860$ dengan $n=30$ sedangkan $X_{\text {tabel }}$ pada taraf signifikan $\alpha$ $=0,05$ diperoleh 42,557 yang lebih besar dari $X_{\text {tabel }}$ sehingga dapat disimpulkan bahwa skor yang diperoleh dari berdistribusi normal.

Tabel diatas menunjukkan bahwa hasil pengujian untuk postest skor $X_{\text {hitung }}=9,964$ dengan $n=30$ sedangkan $X_{\text {tabel }}$ pada taraf signifikan $\alpha$ $=0,05$ diperoleh 42,557 yang lebih besar dari $X_{\text {tabel }}$ sehingga dapat disimpulkan bahwa skor yang diperoleh berdistribusi normal.

2. Uji Homogenitas Varians

Diketahui varians kedua variabel dalam penellitian ini adalah hasil lari 50 meter pada tabel berikut :

\section{Tabel 4.4 Varians Kedua Sampel}

\begin{tabular}{l|l|l} 
& Pretest & Posttes \\
\hline Varians & 1,56 & 0,74 \\
\hline $\mathrm{N}$ & 30 & 30 \\
Kemudian & mencari nilai varians
\end{tabular}

terbesar dan varians terkecil dengan rumus:

Mencari nilai Standar Deviasi dengan menggunakan rumus sebagai berikut:

$$
\begin{aligned}
& \mathrm{SD}=\frac{1}{n} \sqrt{\frac{\Sigma \mathrm{fx}^{2}}{n}-\left(\frac{\Sigma F X}{n}\right)^{2}} \\
& \mathrm{SD}=\frac{1}{\mathbf{3 0}} \sqrt{\frac{75327,583}{30}-\left(\frac{3030}{30}\right)^{2}}
\end{aligned}
$$

$$
\begin{aligned}
& S D=\frac{\mathbf{1}}{\mathbf{3 0}} \sqrt{25101,91-306030} \\
& S D=\frac{\mathbf{1}}{\mathbf{3 0}} \sqrt{2,204,889} \\
& S D=\frac{\mathbf{1}}{\mathbf{3 0}} \mathbf{4 6 , 9 5}
\end{aligned}
$$

$S D=1,56$

Mencari nilai Standar Deviasi dengan menggunakan rumus sebagai berikut:

$$
\mathrm{SD}=\frac{1}{n} \sqrt{\frac{\sum \mathrm{fx}^{2}}{n}-\left(\frac{\sum F X}{n}\right)^{2}}
$$$$
\mathrm{SD}=\frac{\mathbf{1}}{\mathbf{3 0}} \sqrt{\frac{2421,380}{30}-\left(\frac{2430}{30}\right)^{2}}
$$$$
\mathrm{SD}=\frac{\mathbf{1}}{\mathbf{3 0}} \sqrt{808120-306830}
$$

$\mathrm{SD}=\frac{\mathbf{1}}{\mathbf{3 0}} \sqrt{501}$

$\mathrm{SD}=\frac{1}{30} 22,38$

$S D=\mathbf{0 , 7 4}$

Mencari Homogenitas terhadap uji $f$

$$
\begin{aligned}
& \text { fhitung }=\frac{\text { varians besar }}{\text { varians kecil }} \\
& \text { fhitung }=\frac{1,56}{0,74}=2,10
\end{aligned}
$$

Dk pembilng $=\mathrm{n}-1=30-1=29$

Dk penyebut $=\mathrm{n}-1=30-1=29$

Dengan kriteria pengujian sebagai berikut:

Apabila hasil uji homogenitas $F$ hitung $\geq F$ tabel maka data homogen yang artinya varian setiap sampel sama dan apabila hasil uji homogenitas $F$ hitung $<F$ tabel maka data tidak homogen. Nilai $f_{\text {tabel }} 30$ 
pada taraf signifikan $5 \%$ adalah 255. Ternyata Fhitung $>$ Ftabel atau 2,10 < 2,55, maka varians kedua data adalah homogen sehingga analisis korelasi dapat dilanjutkan.

\section{B. Uji Hipotesis}

Setelah diketahui data yang diperoleh dari penelitian memenuhi uji persyaratan yang berdistribusi normal dan homogen, selanjutnya dilakukan pengujian hipotesis. Pengujian hipotesis dilakukan untuk mengetahui Apakah ada Pengaruh Latihan Kekuatan Otot Tungkai Dengan Beban Berbasis Pantai Terhadap Peningkatan Kemampuan Lari 50 Meter Siswa Ekstrakurikuler SMP Negeri 8 Kaur.

$\mathrm{t}=\frac{\sum D}{\sqrt{\frac{n \sum D^{2}-\sum D^{2}}{n-1}}}$

$t=\frac{33,08}{\sqrt{\frac{(30.134,937)-(33,08)^{2}}{29}}}$

$\mathrm{t}=\frac{33,08}{\sqrt{\frac{4048,11-1094,2864}{29}}}$

$t=\frac{33,08}{\sqrt{\frac{2953,8236}{29}}}$

$t=\frac{33,08}{\sqrt{101,8}}$

$t=\frac{33,08}{10,08}=3,28$

Derajat Kebebasan : $=\mathrm{n}-1=30-1=29 t_{\text {tabel }}$ $=1,69913$

Kriteria pengambilan keputusan

Terima Ho jika $t_{\text {hitung }}<t_{\text {tabel, }}$ sebaliknya

Tolak Ho jika $t_{\text {hitung }}>t_{\text {tabel }}$

Jadi nilai $t_{\text {hitung }}>t_{\text {tabel, }}$ dengan nilai $t_{\text {hitung }}=$ 3,28 dan $t_{\text {tabel, }}=1,69913$ sehingga dapat disimpulkan bahwa Terima Ha.

\section{PENUTUP}

Simpulan

Berdasarkan hasil penelitian yang telah diuraikan pada bab terdahulu dapat dikemukakan kesimpulan sebagai berikut: Terdapat Pengaruh latihan kekuatan otot tungkai dengan beban berbasis pantai terhadap peningkatan kemampuan lari 50 meter siswa ekstrakurikuler SMP Negeri 8 Kaur dengan nilai $t_{\text {hitung }}>t_{\text {tabel, }}$ dengan nilai $t_{\text {hitung }}=3,28$ dan $t_{\text {tabel, }}=1,69913$ sehingga dapat disimpulkan bahwa Terima $\mathrm{Ha}$

Saran

Berdasarkan pada kesimpulan diatas maka penulis dapat memberikan saransaran yang dapat membantu mengatasi masalah yang ditemui dalam pelaksanaan kemampuan lari 50 meter yaitu :

1. Bagi siswa yang masih memiliki kemampuan lari 50 meter rendah agar lebih giat dan rutin latihan untuk meningkatkan kemampuannya serta prestasinya, karena olahraga lari 50 meter harus dilatih terus secara berkelanjutan.

2. Bagi pelatih agar memberikan metode latihan yang bervariasi dan efektif untuk peserta ekstrakurikuler sehingga memiliki kemampuan lari 50 meter para atletnya dapat meningkat lebih baik.

3. Bagi peneliti selanjutnya hendaknya bisa memodifikasi jenis latihan lainnya dan melakukan penelitian dengan sampel dan populasi yang lebih luas serta variabel yangberbeda sehingga perlakuanyang diberikan untuk mempengaruhi kemampuan lari 50 meter dapat teridentifikasi lebih luas dalam meningkatkan kemampuan atlet. 


\section{DAFTAR PUSTAKA}

Aisyah, D.K. 2015. Pengaruh Latihan Rope Jump Dengan Metode Interval Training Terhadap Kekuatan Otot Tungkai. Jurnal kesehatan olahraga http://digilib.unm.ac.id/files/disk1/7/ universitas\%20negeri\%20makassardigilib-unm-suriahhana-318-1-1.ibush.pdf. (Diakses 28 januari 2019 pukul 20,00 wib)

Bintoro, R.T. 2015. Perbendingan Tingkat Daya Ledak Tungkai Siswa Peserta Ekstrakurikuler Bola Voli Di Kabupaten Kebumen Antara Siswa SMK Negeri 1 Puring Dengan Siswa SMK Negeri 2 Kebumen : Universitas Negeri Yogyakarta

Candra, Roky. 2015.Hubungan kecepatan lari 50 meter dan kekuatan otot tungkai terhadap kemampuan lompat jauh siswi kelas XI MIPA 2 sosiologi SMA Negeri 1 Bengkulu Selatan

Chan, Faizal. 2012. Strength Training (Latihan Kekuatan). Jurnal Cerdas Sifa Pendidikan. https://www.online journal.unja. ac.id/index. php/csp/article /download/ 703/631. (Diakses 26 januari 2019 pukul 19,00 wib)

Hanafi, Suriah. 2010. Efektifitas Latihan Beban Dan Latihan Pliometrik Dalam Meningkatkan Kekuatan Otot Tungkai Dan Kecepatan Reaksi. Jurnal ILARA. https://jurnalmahasiswa.unesa.ac.id/i ndex.php/jurnal-kesehatanolahraga/article/viewFile/11171/7666 . (Diakses 26 januari 2019 pukul 20,00 wib)
Handoyo, A. 2010. Lari Jarak Pendek. Jakarta: Nobel Edumedia

Kurniawan, Feri. 2011. Buku Pintar Olahraga. Jakarta: Laskar Askar

Lubis, Johansyah. 2013. Panduan Praktis Penyusunan Progaram Latihan. Jakarta: PT Raja Grapindo Persada

Nurhasan, 2001. Tes dan Pengukuran Dalam Pendidikan Jasmani. Jakarta : Direkorat Jendral Olahraga

Prasetiyo, Adi. 2015.Pengembangan Media Belajar Pendidikan Jasmani Olahraga Dan Kesehatan Materi Guling Depan Untuk SMP kelas VI. Universitas Negeri Yogyakarta

Pujianto, Dian, dkk. 2013. Dasar-Dasar Penelitian Pendidikan Jasmani. Bengkulu: FKIP Universitas Bengkulu

Rakhmawati, S,D. 2017. Peningkatan kemampuan lari sprint dengan menggunakan metode latihan lari di pasir pada siswa peserta ekstrakurikuler atletik SMK Negeri 1 Gombong Kabupaten Kebumen: Universitas Negeri Yogyakarta

Riwansyah, R. 2016. Kontribusi daya ledak otot tungkai terhadap kecepatan lari sprint 50 meter pada Mahasiswa semester IV Penjaskesrek Universitas Bengkulu

Saputra, Hengki. 2017. Pengaruh Latihan Lari Bolak-balik Menggunakan Beban Kaki Terhadap Peningkatan Kemampuan Dribbling Pada Pemain Futsal Jugador Andalas FC Kota Bengkulu: Universitas Bengkulu 
Sidik, D,Z. 2014. Mengajar dan Melatih Atletik. Bandung: PT Remaja Rosdakarya

Subagiyo. 2004. Perencanaan Pembelajaran Penjaskesrek. Jakarta: Universitas Terbuka

Sugiyono. 2013. Metode Penelitian Kuantitatif, Kualitatif, dan R\&D. Bandung: Alfabeta, CV . 2016. Metode Penelitian Kuantitatif, Kualitatif, dan R\&D. Bandung: Alfabeta, CV

Wiarto, Giri. 2013. Atletik. Yogyakarta: Graha Ilmu . 2013. Fisiologi dan Olahraga. Yogyakarta: Graha IImu

Widodo,.dkk. 2014. Perbedaan Latihan Lari Cepat Ditambah Latihan Double Leg Bound dan Alternate Leg Bound Terhadap Kecepatan Lari 50 Meter Pada Pelari Pemula. Journal of Sport Sciences and Fitness. http://journal.unnes.ac.id/sju/index.p hp/jssf/article/download/6237/4704.

(Diakses 2 maret 2019 pukul 17,00 wib). 